\title{
Study on the Intercultural Communicative Competence from the Perspective of the Silk Road Social Pragmatic Failures
}

\author{
Yuanmin Zhang ${ }^{1}$, Gailin Liu \\ ${ }^{1}$ Xi’an University of Technological Information, Xi’an, Shaanxi, 710025
}

Keywords: Silk Road, Social Pragmatic Failure, Intercultural Communicative Competence

\begin{abstract}
Silk Road is a trans-Asia, connecting the Eurasian continent's international channel, is a bridge between Chinese and Western cross-cultural communication. "Silk Road Economic Zone" and "21st Century Maritime Silk Road" together "together all the way" is an important strategy for China in the new era, for China, along the Silk Road countries and countries around the world are of great significance. Based on the theory of pragmatics, this paper analyzes the social pragmatic failures in cross - cultural communication on the Silk Road from the perspective of cultural differences and how to improve the cross - cultural communication ability on the Silk Road.
\end{abstract}

\section{Introduction}

2013 Xi Jinping President proposed the "Silk Road economic zone" strategy to build China and the Asia-Pacific economic circle and the European economic circle network. [1] Silk Road is an important link between Chinese and foreign exchanges, China and the Silk Road on the other countries of cultural exchanges in a typical example of cross-cultural communication, along this channel, cross-cultural exchanges to continue to develop smoothly. Silk Road along the dozens of countries and regions, countries in geography, history, religion, language, culture, policy, development stage and so on are very different. According to the radiation range of the Silk Road economic zone and the official language of the relevant countries along the line, the key language for the Silk Road economic belt contains as many as 24 kinds of Russian. Language is not isolated, it is deeply rooted in the national culture, and reflects the nation's faith and emotion. Language and culture are closely linked, all verbal communication is in a certain cultural background to start. In the cross-cultural communication on the Silk Road, language communication is the most direct and the most important way. Because of the different social and cultural environments of multiple languages, each has its own uniqueness. If we inadvertently understand these cultural differences, there will be in the Silk Road cross-cultural communication in a variety of pragmatic failures lead to cross-cultural communication failure. The main pragmatic failure in the process of cross - cultural communication on the Silk Road is social pragmatic failure. However, based on the theory of pragmatics, this paper tries to analyze the social pragmatic failures on the Silk Road from the perspective of interculturalism. Therefore, this paper attempts to explore the social pragmatic failures on the Silk Road from the perspective of intercultural communication. How to Improve the Intercultural Communicative Competence of Silk Road.

\section{Cross-cultural communication in the pragmatic causes of failure}

In the intercultural communication, the Chinese and English lexical syntactic structure is completely equivalent, and in fact, many grammatical syntactic structures in English can not correspond to the corresponding Chinese, which often leads to cross-cultural pragmatic failure source. Some English vocabulary is often more semantics than the Chinese word "see" see "see, see; check, prosecute; understand, understand; experience, experience; visit, meet; attention, attention, accompanied, send" The at the same time some Chinese vocabulary semantics than English words 
to be broad, such as "take" the verb can be "take, bring, carry, fetch" and other words to express. The syntactic structure in English is very different from that of Chinese. English is often used to express complex sentence structure with compound sentence or compound sentence. Chinese is used to express complex sentences by means of conjunctions or punctuation. For example: "We are happy that much much changing changing in China for the better and we are happy to be part of this renewal process by what we teach our students." The Chinese expression is "We are pleased with China's great improvement and It is a pleasure to contribute to this revitalization process through our teaching. "It can be seen that the different syntactic structures of both languages in both English and Chinese also have a great influence on the understanding of the language in intercultural communication, which, if not Attention, it is easy to lead to pragmatic mistakes.

Due to cross-cultural communication background, mistakenly the language of the use of language and the way to dialogue into the dialogue, resulting in the failure of communication. People of different cultural backgrounds have a set of customary habits. In cross-cultural communication activities, people always used to use their own way of speaking to explain each other's words, it is natural to use the language of the language into the cross-cultural context, resulting in language errors, resulting in mutual understanding can not be properly understood Barriers to communication. As the two sides in different social, historical, cultural, geographical, background and other factors under the long-term impact, so the two sides of the value of standards, thinking patterns and expressions of etiquette are different. Western society pays attention to personal values Individual ethics becomes its basic guiding ideology, and in contrast, Chinese social tradition social values are tolerant and benevolent ethics. English cultural background of the pursuit of freedom and differences, public and private, frank and direct, and Chinese cultural background of the people are often humble, subtle, maintain a good relationship, stress harmonious coexistence. The ritual gap between the East and the West is greater, such as the expression of polite language. English cultural background of the majority of people are not hesitate to praise others, when the English cultural background of the people received praise or praise, often say "Thank you" to accept the praise of others. While the opposite of the Chinese cultural background of people are often humble and deny the authenticity of others to praise the courtesy. For example, in the recognition or praise of others, Chinese cultural backgrounds tend to use "where, where" "ashamed, ashamed" and other self-deprecating form of courtesy to express self-humility to others courtesy and gratitude. In ancient China, women look directly at men as a taboo, while the British people chat, but also try to look directly at each other's eyes, this is a polite expression, so that the other side know that I was listening. And modern, we also asked to communicate with others, to look at each other's eyes, was triangular shape.

Thinking patterns and customs of different. Culture will affect people's views and understanding of the outside world, different countries have different cultures, so there must be differences in the thinking mode, which is particularly evident between the East and West culture. Western cultural thinking mode focuses on logic and analysis, while the oriental culture of thinking mode is to show intuitionistic integrity, which is also the characteristics of traditional Chinese culture thinking. In essence, the mindset tends to ignore the differences of individual things, exaggerate the cognitive attitudes associated with a particular social group, often with emotional, and with a fixed creed. In all the fixed potential, some fixed potential is correct, and some are wrong, will directly affect the cross-cultural communication, resulting in communication errors. Ethnic customs and habits, refers to a people in the production, living, eating, dressing marriage, funeral, festivals, celebrations, ceremonies and other material and cultural society common preferences, practice and taboo. Custom is a nation in the long history of the gradual development of the formation, but also with the changing changes in living conditions. Especially in the festival is clearly different, such as the Chinese New Year to celebrate the new year, while the West to Christmas to meet the new year.

\section{The Silk Road on the cross-cultural communication}

Intercultural communication refers to the communication between people of different language and cultural backgrounds. Intercultural communication is one of human communication behaviors. 
From two thousand years ago, Zhang Qian to the Western Regions to the Silk Road in 2014 successfully selected the world cultural heritage list, the Silk Road has been far beyond the "road" geographical category and "silk" material category, as China and silk On the road to other countries of the cultural exchanges of a typical example of cross-cultural communication. The Silk Road is not only a channel for communication between China and Eurasian countries, but also a bridge between East and West cultures. Silk Road on the many nationalities, different languages, Silk Road, the official language of about 24 kinds of multiple languages different social and cultural environment, each with its unique. Language and culture are closely linked to the language of the cultural background of the language must be a profound impact. Saar pointed out: the language does not exist from the culture, that is, not from the community handed down, we decided to live the customs and beliefs of the overall [2]. Language and culture are inseparable, language is the carrier of culture, while culture also reflects the language. As we all know, cross-cultural communication behavior is a kind of social and cultural behavior, it occurs in society and by culture, psychology and other factors influence and constraints. Although the important tool of intercultural communication is language, but cultural factors affect the whole process of communication. Silent road cross-cultural communication is not only based on voice, grammar and lexical language communication, but in a specific social and cultural environment to language as a tool for social communication. If we understand the silence of the famous culture along the Silk Road, we can not easily deduce the pragmatic meaning of both sides of the communication, and it is easy to form pragmatic failures in cross-cultural communication. People between the communication, then we will lose marketing or business opportunities.

\section{The Silk Road on the social pragmatic mistakes}

Pragmatic failure does not mean that the language used in the sentence of the general sentence is wrong, but it is wrong to speak inappropriate, or if the words are not properly spoken, the expression is not accustomed to, so that the communication can not achieve the desired effect. According to the British linguist Thomas (Jenny Thomas) in 1983, "cross-cultural pragmatic failure (Cross-cultural Pragmatic failure)", "pragmatic failure can not understand the meaning of discourse" [3]. In short, pragmatic failure is from the specific context, contrary to the unique cultural values of the target language, regardless of the identity of both sides of the communication, status, occasions, and other language barriers encountered in the use of language errors. Thomas argues that in speech communication, the speaker has a grammatical error, at least considered to be "bad"; but violating the rules of communication, such as politeness, will be considered "bad behavior" and is considered "not sincere", Deliberately deceived or bad people "[4]. (He Natural 2004: 169) Thomas divides it into linguistic pragmatic failures and social pragmatic failures according to the root causes of pragmatic failures. Linguistic pragmatic failure is related to the rules of language composition, which means that the speaker can not use the language form and language structure used by the native speakers in the same occasion when expressing the specific intention or implementing the specific language behavior. Social pragmatic failure is due to the communication of the party in the process of communication in the mother tongue culture is different from the target language culture of social pragmatic rules or pragmatic parameters caused by [5]. The pragmatic failure of language is caused by the negative transfer of language form, and the social pragmatic failure is caused by the negative transfer of pragmatic culture. In the cross-cultural communication on the Silk Road, because of the differences in national culture, people of different cultures directly translate their own discourse into target language when they communicate with each other, and unconsciously subconsciously use their own cultural norms and values, Way of thinking, national psychology to guide their words and deeds and ideas, and as a standard to judge others words and deeds and ideas. Therefore, in the process of cross-cultural communication on the Silk Road, the main pragmatic failure is social pragmatic failure. Language pragmatic failure only affects whether the communication is achieved, and the harm to the emotion is slight, then the social pragmatic failure is due to social and cultural differences such as social and cultural rules, social distance, thinking habits, language psychology, values, customs and so easily lead to misunderstanding, resulting in 
serious injury to the feelings, leading to communication failure even more serious consequences. Native speakers are more likely to forgive people in different cultures in the language of the mistakes, because language errors are caused by low language skills. But the social pragmatic failure will be unacceptable, and even think that the speaker is interested in that, is a quality problem, which is bound to cause serious misunderstanding, leading to the Silk Road cross-cultural communication failure. Silk Road east of the western Pacific coast, west to the Baltic Sea, across the Asia-Europe continent, including China, Russia, India, Kazakhstan and other countries. Most of the countries along the Silk Road are Russian-speaking countries after the disintegration of the Soviet Union, and the exchanges and cooperation in the fields of economy, culture and science and technology are used in Russian as a common language. Therefore, this paper analyzes the social pragmatic mistakes on the Silk Road based on the Russian language of the Silk Road economy.

Example 1 There is a Chinese student who does not understand Russian culture and greets a Russian woman by saying that she is "aunt" according to Chinese polite habits. The lady is followed by anger. Later, the young man is puzzled and apologized. It is clear that because the Chinese students in the communication do not understand in the Russian culture "aunt" as a social address language is often used for preschool children and junior students called unfamiliar adults. If adults call them unfamiliar middle-aged people, it is vulgar and impolite. Cultural differences lead to a deeper shift in social pragmatic failures.

Example 2 When the "Russian girl in Harbin" is in the process of shooting, the Chinese director to the Russian actor promised "two days I took you to the karaoke OK to play." Two days later, a few Russian girls dressed up, ready to go, the director to confused. Because in the Chinese "one or two days" is an uncertain concept of time, and in Russian is a specific time, so several girls complain that the director should not keep promise. Both sides use their own cultural background to guide their own words and deeds, and as a standard to judge others' words and actions and ideas to cause social pragmatic failures lead to cross-cultural communication failure.

Example 3 When we bid farewell to Russian guests, we often use the "careful on the road", "careful", "slow driving", "walking" and so on, given the goodwill given

Suggestions, and in Russian culture this suggestion means that we do not trust him to be able to safely go home, do not you go slow, hurry is not it better? As the two sides of the communication did not realize the existence of cultural differences, resulting in social errors.

Example 4 Chinese businessmen see a Russian boy is very cute to praise that "the boy so cute, lively!" The boy was unhappy after listening to the boy. It is clear that this communication did not achieve the purpose of communication. In the Chinese culture, the dragon is a symbol of nobility and auspicious, idiom "hopeful", which means that parents want their children to do something, "Dragon Tiger" describes the vibrant scenes, so the Chinese businessmen with "lively" to praise the boy, and He did not realize that the dragon in the Russian culture is "evil" in the symbol of cross-cultural communication failure.

Example 5 in the Russian market often see such a situation Chinese people asked the Russian customers "do not want", which makes the Russian people are very surprised, and then walked away in an atmosphere. For this question the Russians understood as "whether or not? Do not hurry to leave!", Which would make them feel that the questioning was so stupid that they would not stay in his (her) store. However, in Chinese culture, we often

With positive and negative combination of the lyrics for doubt: okay? Come not to use? Do not? "Do not", this question in the Chinese commodity trading is a common language.

Example 6 China and South Korea are deeply influenced by Confucian culture, but even so, there are various social pragmatic failures in cross-cultural communication. A South Korean student, when expressing his blessing to a newlywed Chinese teacher, said, "I wish you a son like toad." This makes this very angry for newly married Chinese couples. Korean culture toad refers to filial piety, kind-hearted, healthy body of the man, but in the Chinese culture toads commonly known as toad, toad who has a lot of pimple, the body toxic, extremely ugly appearance. In Chinese there is an idiom called "toad want to eat swan", metaphor people do not know the self, bent on trying to get something that can not get. As the Korean students do not understand the cultural differences 
between China and South Korea caused by social pragmatic failures lead to communication failure.

Case 7 In a Chinese and Hungarian business negotiations, the Chinese delegation could not accept the Hungarian program, but the politician did not directly reject the rhetoric, but said, "I am afraid we need to discuss and discuss." When the Hungarian delegation heard "re-discussion"

\section{How to improve the cross-cultural communication skills on the Silk Road}

Silk Road is the cradle of world civilization, multi-ethnic integration of the humanities region, the East-West cultural exchange bridge. With the deepening of exchanges between countries, Silk Road cultural exchanges more and more frequent, more extensive scope of communication. In the cross-cultural communication of the Silk Road, social pragmatic failures have occurred frequently, resulting in communication barriers, intercourse interruption, and even hostility and hostility between the two sides of communication. How to avoid social pragmatic failure in cross - cultural communication on the Silk Road to carry out effective cross - cultural communication. First of all, effective cross-cultural communication and to avoid cultural conflict is the prerequisite and basis for the exchange of cultural and educational exchanges along the Silk Road. To cooperate with the Silk Road countries along the mode of cooperation to understand the Silk Road economic belt geography, history, economy, politics, culture and other related knowledge, through the Confucius Institute to promote Chinese teaching and the spread of Chinese culture, along the Silk Road The country has a deeper understanding of Chinese culture. Secondly, the social pragmatic mistakes on the Silk Road are related to the cultural background, mostly because the two sides of the communication do not understand each other's cultural background. In the cross-cultural communication, to understand each other's cultural background and social occasions, habits and attitudes, to develop communicators cross-cultural communication awareness, to develop good communication habits, which can combine context, with appropriate language and culture Background knowledge and the communication of different ethnic objects smoothly cross-cultural communication, and truly have the ability to cross-cultural communication. Finally, most of the countries along the Silk Road economic zone use Russian as the common language for the exchange and cooperation in the fields of economy, culture, politics and science and technology in Russian countries. So we need to open in the country's major institutions of Russian professional and Russian training, so as to cultivate more Russian-speaking international compound talents.

\section{Conclusion}

In the cross-cultural communication on the Silk Road, people have different ways of speaking or speaking in different cultural backgrounds. Therefore, to avoid the Silk Road on the social pragmatic mistakes, improve the Silk Road cross-cultural communication skills, still need to pay more attention to the Silk Road cultural differences, and more accumulated experience. In the process of intercultural communication on the Silk Road, we should fully realize that the culture of a nation can only learn from the culture of the foreign peoples and frictions with the culture of other peoples. The collision is likely to be further developed and treated rationally The cultural conflict between different peoples should not only recognize the existence of cultural conflict, but also respect the culture of the target country in cross-cultural communication, try to reduce the conflict and confrontation as much as possible. We hope that through our efforts to contribute to the ideal of harmonious coexistence between cultures, we can build the beauty of the United States, beauty of beauty, beauty and beauty, and the world.

\section{References}

[1] Huangfu Xiaotao, the re-globalization of Chinese culture [M]. Beijing: Guangming Daily Publishing 2016.

[2] What natural, "Pragmatics and English learning" [M], Shanghai, Shanghai Foreign Language Education Press, 1997. 
[3] He natural, "Introduction to Pragmatics" [M], Changsha, Hunan Education Press, 1988.

[4] Liu Yinghua screen road [M], Nanjing: Jiangsu people published 2014.

[5] Ma Shuhua. Pragmatic failure and teaching Chinese as a foreign language [J]. Yulin Teachers College, 2009 (1): 124.

[6] Li Linzhang, on the rhetoric of rhetoric in language and language, 2000,173 